\title{
TRATAMENTO BIOLÓGICO DE DRENAGEM ÁCIDA DE MINA: ENSAIO DIFERENCIAL PARA AVALIAÇÃO DA ADESÃO DE BIOMASSA EM PARTÍCULA LITEBALL
}

\author{
S. L. P BORGES ${ }^{1}$, G. F. SAMPAIO ${ }^{1}$, R. P. RODRIGUEZ ${ }^{1}$ e G. P. SANCINETTI ${ }^{1}$ \\ ${ }^{1}$ Universidade Federal Alfenas, Instituto de Ciência e Tecnologia \\ E-mail para contato: gisellesancinetti@gmail.com
}

\begin{abstract}
RESUMO - Os principais impactos ambientais produzidos pela atividade de mineração decorrem dos estéreis e rejeitos ricos em sulfetos de ferro que se oxidam em presença do ar, da água e da ação de bactérias do gênero Acidithiobacilus, desencadeando o processo de acidificação de drenagens e a dissolução de metais, originando a drenagem ácida de mina (DAM). Os métodos químicos empregados para o tratamento de DAM apresentam elevado custo operacional, o que torna o tratamento biológico anaeróbio uma alternativa tecnicamente viável para o tratamento destas águas. Dentre as diversas configurações de reatores empregadas para o estudo da redução anaeróbia do sulfato e para o tratamento da drenagem ácida de mina está o reator anaeróbio de leito fluidificado (RALF). Este trabalho consistiu na realização de ensaios em reatores diferenciais para avaliação da adesão de biomassa na partícula Liteball, fornecida pela empresa Mineração Curimbaba. A relação DQO/ $\mathrm{SO}^{-2}{ }_{4}$ empregada foi de 1,0 para DQO de $500 \mathrm{mg} / \mathrm{dm}^{3}$. Os ensaios foram realizados em 28 dias, sendo a taxa de colonização observada de 0,3348 g SVT/(g suporte.dia).
\end{abstract}

\section{INTRODUÇÃO}

Muitos dos impactos ambientais são resultantes da atividade mineradora, os quais podem comprometer, principalmente, a vida aquática. Quando nos resíduos minerais estão presentes sulfetos, estes são uma significativa fonte para a drenagem ácida de mina (DAM). A ocorrência da DAM se dá pela solubilização dos metais pesados devido ao baixo pH do meio, ou pela oxidação da pirita a ácido sulfúrico. Suas principais fontes são as minas a céu aberto ou subterrâneas, bacia de rejeitos, pilhas do estéril e de estocagem do minério que contenham sulfetos associados (Almeida, 2005; Menezes, 2004; Rodriguez, 2010).

Para o tratamento da drenagem ácida de mina, normalmente, utilizam-se métodos passivos, uma vez que apresentam baixo custo e pouca manutenção ou, a neutralização química e a precipitação dos hidróxidos metálicos, por meio de substâncias alcalinas. Ao tentar recuperar áreas afetadas com a drenagem mineira por meio do tratamento físico-químico, tem-se um processo caro, uma vez que, os reagentes químicos possuem alto custo e, estas áreas possuem $\mathrm{pH}$ baixo, condutividade específica elevada e concentrações elevadas de ferro, alumínio e manganês (Akcil, 2006; Rubio, 2012). 
No tratamento biológico utilizam-se processos microbiológicos com intuito de diminuir a acidez e os metais dissolvidos, incluindo as lagoas e biorreatores aeróbios e anaeróbios. Há duas formas de se atingir a redução biológica do sulfato, por meio de células suspensas ou imobilizadas. A utilização de reatores contínuos com células suspensas está associada a baixas vazões de escoamento e altos tempos de residência para evitar o arraste das células. Os reatores com células imobilizadas normalmente oferecem maior resistência a condições extremas de $\mathrm{pH}$ e a altas concentrações de metais (Tang et al., 2009).

\section{OBJETIVOS}

O objetivo do presente trabalho consistiu na avaliação da adesão de biomassa anaeróbia em meio suporte Liteball, fornecido pela Mineração Curimbaba, utilizando etanol como fonte de carbono para tratamento de drenagem ácida de mina. Desta forma foram estabelecidos os seguintes objetivos específicos: (DQO).

a) avaliação da eficiência de conversão de sulfato em sulfeto e remoção da carga orgânica

b) avaliação de adesão microbiana no material suporte através da análise de sólidos voláteis totais.

\section{REVISÃO BIBLIOGRÁFICA}

\subsection{Drenagem Ácida de Minas (DAM)}

A drenagem ácida de minas é formada quando a pirita $\left(\mathrm{Fe}_{2} \mathrm{~S}\right)$ e outros minerais sulfetados são oxidados espontaneamente, devido a presença de oxigênio e água, produzindo ácido sulfúrico que dissolve metais presentes no solo/rocha (Tang et al., 2009).

Existem vários métodos de tratamento de DAM utilizados para alcançar os níveis de descarte de poluentes permitidos pela legislação. Os sistemas de tratamentos convencionais envolvem neutralização e precipitação pela adição de substâncias alcalinas, como pedra calcária, lima, hidróxido ou carbonato de sódio. As desvantagens desta tecnologia são a produção de grandes quantidades de lodo, que devem ser dispostas de maneira adequada, envolvendo altos custos, a necessidade de uma grande dose de material alcalino para manter o $\mathrm{pH}$ acima de 6,5 e, os íons metálicos presentes na DAM não são recuperados. Tais fatores justificam o emprego de pesquisas para aplicação do processo biológico no tratamento da DAM.

\subsection{Tratamento Anaeróbio Utilizando as Bactérias Redutoras de Sulfato (BRS)}

Devido às diversas vantagens sob os processos aeróbios, principalmente os baixos custos inicial e operacional, as tecnologias anaeróbias para o tratamento de águas residuárias ganharam popularidade ao longo dos anos (Chernicharo, 1997). 
O processo que utiliza as bactérias redutoras de sulfato (BRS) tem recebido constante atenção para o tratamento de efluentes com alto teor de sulfato. Essas bactérias utilizam sulfato como aceptor de elétrons e o reduzem a sulfeto. Com a redução, há a geração de alcalinidade, o que resulta no aumento do $\mathrm{pH}$ e na precipitação dos metais pesados como sulfetos e carbonatos (Knobel et al., 2002).

A redução biológica do sulfato pode ser atingida por meio de células suspensas ou imobilizadas. A utilização de reatores contínuos com células suspensas está associada a baixas vazões de escoamento e altos tempos de residência para evitar arraste das células. Os reatores com células imobilizadas normalmente oferecem maior resistência a condições extremas de $\mathrm{pH}$ e altas concentrações de metais. Para o crescimento da biomassa, os microrganismos necessitam, além de um doador de elétrons, uma fonte de carbono. As BRS podem utilizar diretamente como fonte de carbono substratos simples, como etanol e hidrogênio.

A eficiência dos reatores com células imobilizadas depende do material suporte utilizado para imobilizar a biomassa, pois o tipo e número de células aderidas variam de acordo com as características do material e podem ser severamente afetadas por várias propriedades físicoquímicas do meio suporte.

De acordo com Tang et al. (2009) foram desenvolvidos alguns estudos sobre a redução anaeróbia de sulfato associado ao tratamento da drenagem ácida de minas, que foram desenvolvidos utilizando etanol, metanol e lactato como fonte de carbono.

Estudos em reator granular de leito expandido foram feitos com metanol como fonte de carbono apenas para a produção de metano e acetato. O efeito inibidor do sulfeto nos microrganismos metanogênicos foi observado apenas quando a concentração de sulfeto esteve acima de $1,2 \mathrm{gS} / \mathrm{dm}^{3}$. Para a relação $\mathrm{DQO} / \mathrm{SO}_{4}{ }^{-2}$ de 0,34 houve favorecimento da redução do sulfato.

Rodriguez (2010) avaliou a remoção de sulfato em águas de drenagem ácida de minas em reatores UASB (reator anaeróbio de manta de lodo) e reator anaeróbio horizontal de leito fixo (RAHLF). Para o RAHLF os resultados mostraram que a redução da carga de sulfato aplicada foi o fator determinante para bons resultados de remoção (70 \% de remoção de sulfato e $75 \%$ de remoção de $\mathrm{DQO})$. A relação $\mathrm{DQO} / \mathrm{SO}_{4}{ }^{-2}$ igual a 0,67 permitiu eficiência de remoção de sulfato acima de $70 \%$ com pequeno acúmulo de ácido acético no efluente. Para o reator UASB a relação $\mathrm{DQO} / \mathrm{SO}_{4}{ }^{-2}$ igual a 1,0 promoveu melhora a eficiência do reator.

\section{MATERIAIS E MÉTODOS}

\subsection{Reatores diferenciais}

Os reatores, produzidos em acrílico, possuíam 5,0 cm de comprimento e 2,0 $\mathrm{cm}$ de diâmetro, com volume total de $30 \mathrm{ml}$. A Figura 1 mostra o reator diferencial. 


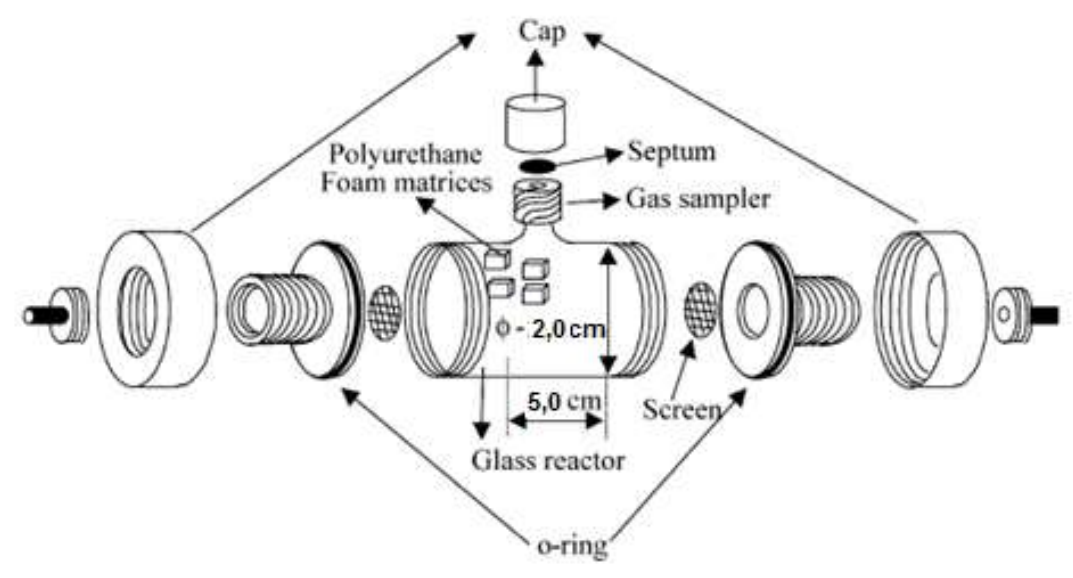

Figura 1 - Esquema do reator diferencial (Ribeiro et al., 2005).

\subsection{Meio suporte para imobilização da biomassa}

As partículas usadas como meio suporte para a imobilização da biomassa foram o Liteball fornecido pela empresa Mineração Curimbaba, sediada em Poços de Caldas - MG.

Esse material possui características atrativas para ser utilizado como meio suporte, tais como: densidade aparente de $2,56 \mathrm{~g} / \mathrm{cm}^{3}$, diâmetro médio de $0,897 \mathrm{~mm}$, alta porosidade e área superficial, além disso, é um resíduo da indústria de mineração. A escolha foi principalmente devido a possibilidade de reaproveitar resíduos industriais, além da flexibilidade de utilização em diversas configurações de reatores, como por exemplo, o reator de leito fluidizado. Além disso, existe interesse da empresa nesta possibilidade de aplicação do material, que pode acarretar desenvolvimento de novos produtos pela mesma.

Com o intuito de retirar o fino, as partículas foram peneiradas, utilizando malha de 28 mesh com abertura de $600 \mu \mathrm{m}$.

\subsection{Inoculo}

Como inoculo foi utilizado lodo proveniente de reator anaeróbio de manta de lodo aplicado para tratamento de água residuária de abatedouro de aves da empresa Avícola Dacar, sediada em Tietê - SP.

Para os ensaios de adesão do biofilme, a biomassa, a princípio na forma de grânulos, foi previamente triturada em liquidificador. O inoculo possuía uma concentração de sólidos voláteis totais de $54,26 \mathrm{~g} / \mathrm{dm}^{3}$.

\subsection{Drenagem Ácida de Minas (DAM) e fonte de carbono}

Para alimentação dos reatores foi utilizada DAM sintética com pH de aproximadamente 4,0 e concentração de sulfato e DQO de $500 \mathrm{mg} / \mathrm{dm}^{3}$ e etanol como fonte de carbono. A composição da 
DAM em $\mathrm{mg} / \mathrm{dm}^{3}$ era formada por: $\mathrm{MgSO}_{4}$ (110), $\mathrm{FeSO}_{4} \cdot 7 \mathrm{H}_{2} \mathrm{O}$ (49), $\mathrm{ZnCl}_{2}(15), \mathrm{NH}_{4} \mathrm{Cl}(115,4)$, $\mathrm{NaH}_{2} \mathrm{PO}_{4}(68,2)$ e $\mathrm{Na}_{2} \mathrm{SO}_{4}(600)$.

\subsection{Procedimento experimental}

Quatro reatores foram preenchidos com Liteball, com massa conhecida, e colocados em câmara termostática com temperatura controlada de $30^{\circ} \mathrm{C}$. A alimentação foi feita por bomba peristáltica em rotação de $6 \mathrm{rpm}$ de modo a manter o TDH de 24 horas. A solução de alimentação foi mantida em geladeira sob temperatura de $15^{\circ} \mathrm{C}$ e agitação constante por meio de agitador magnético.

O início da operação dos reatores ocorreu com a alimentação de solução contendo $300 \mathrm{mg} / \mathrm{dm}^{3}$ de inóculo, solução de DAM sintética e etanol. $\mathrm{O}$ pH era corrigido com $\mathrm{HCl}$ para 4,0, caso necessário.

A cada 7 dias um reator era interrompido para realização das análises de adesão microbiana, que era quantificada pela análise de sólidos voláteis totais. O final do experimento ocorreu após 28 dias de ensaio, quando o último reator diferencial foi analisado em relação à adesão.

\subsection{Análises Físico-Químicas}

O sistema foi avaliado através da realização de análises físico-químicas das amostras de afluente e efluente dos reatores, realizados 3 vezes por semana.

As análises de DQO, $\mathrm{pH}$, sólidos voláteis totais e sulfato seguiram os métodos descritos pelo APHA (2012).

\section{RESULTADOS E DISCUSSÃO}

As Figuras 1 e 2 apresentam os resultados de remoção de carga orgânica (DQO) e sulfato, respectivamente, ao final de cada ciclo de 7 dias. Segundo Rodriguez e Zaiat (2011) baixas conversões de sulfato e baixa remoção de carga orgânica são esperadas devido ao pequeno volume do reator, o que proporciona baixo tempo de detenção hidráulica no sistema.

Na Figura 3 está apresentada a retenção de biomassa dada em massa de sólidos voláteis totais por massa de material suporte em função do tempo de operação dos reatores. É possível notar que até 21 dias houve aumento da retenção de forma lenta e gradativa, no período entre 21 e 28 dias o aumento da retenção foi consideravelmente alto.

A Figura 4 mostra a taxa de colonização ao longo do período de 28 dias. Observa-se que entre os primeiros 14 dias experimentados houve um decaimento da taxa. Após essa queda inicial, ela se manteve estável ao longo de mais 7 dias. No $28^{\circ}$ dia, nota-se um acentuado aumento. 


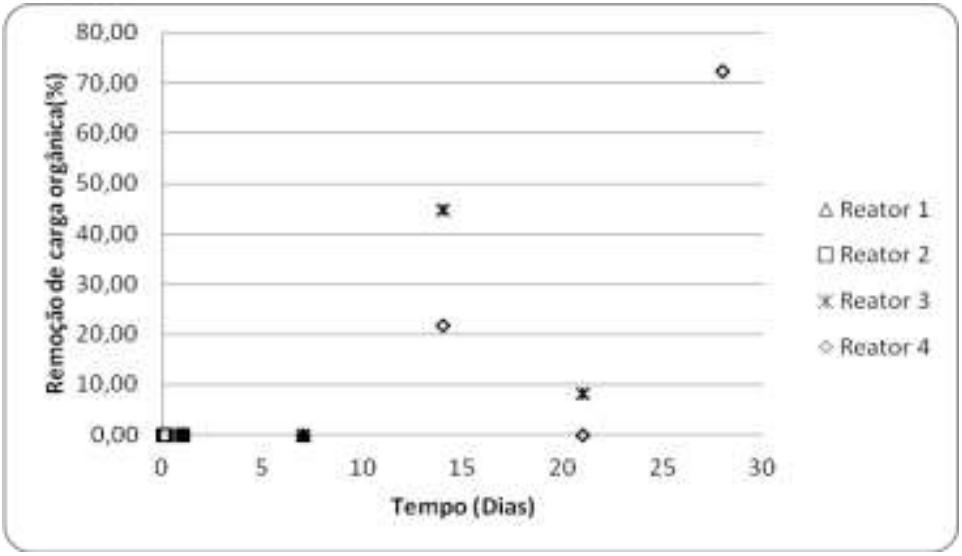

Figura 1 - Percentual de remoção de DQO.

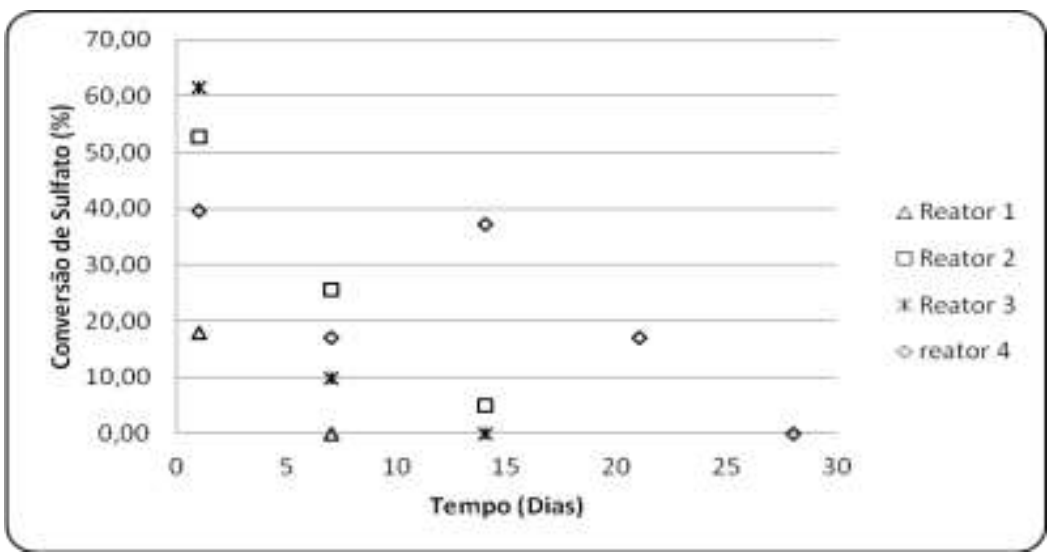

Figura 2 - Percentual de conversão de sulfato a sulfeto

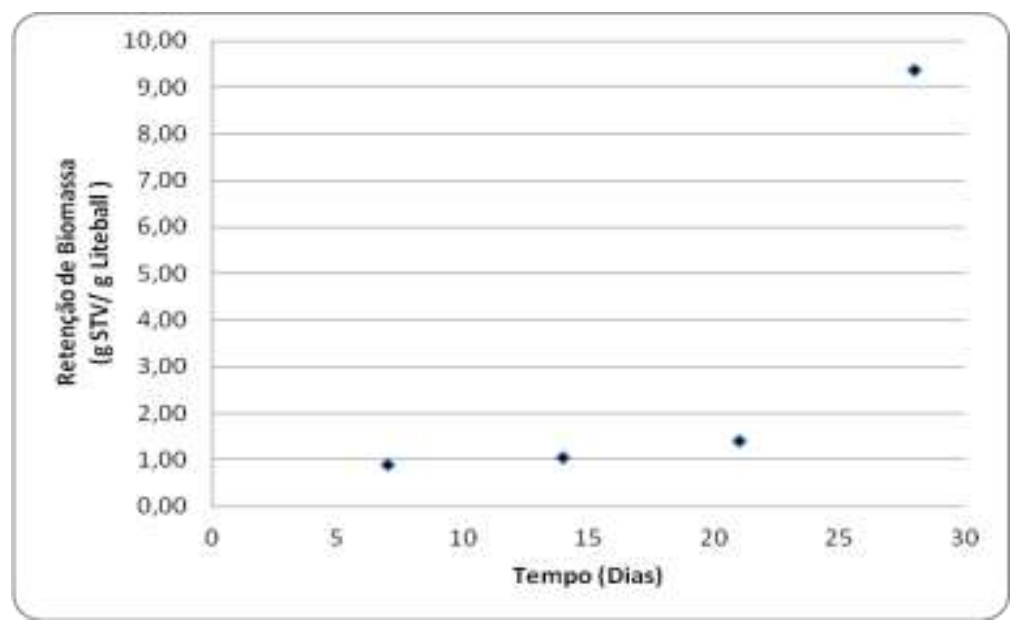

Figura 3 - Retenção de biomassa dada em massa de sólidos voláteis totais por massa de material suporte. 


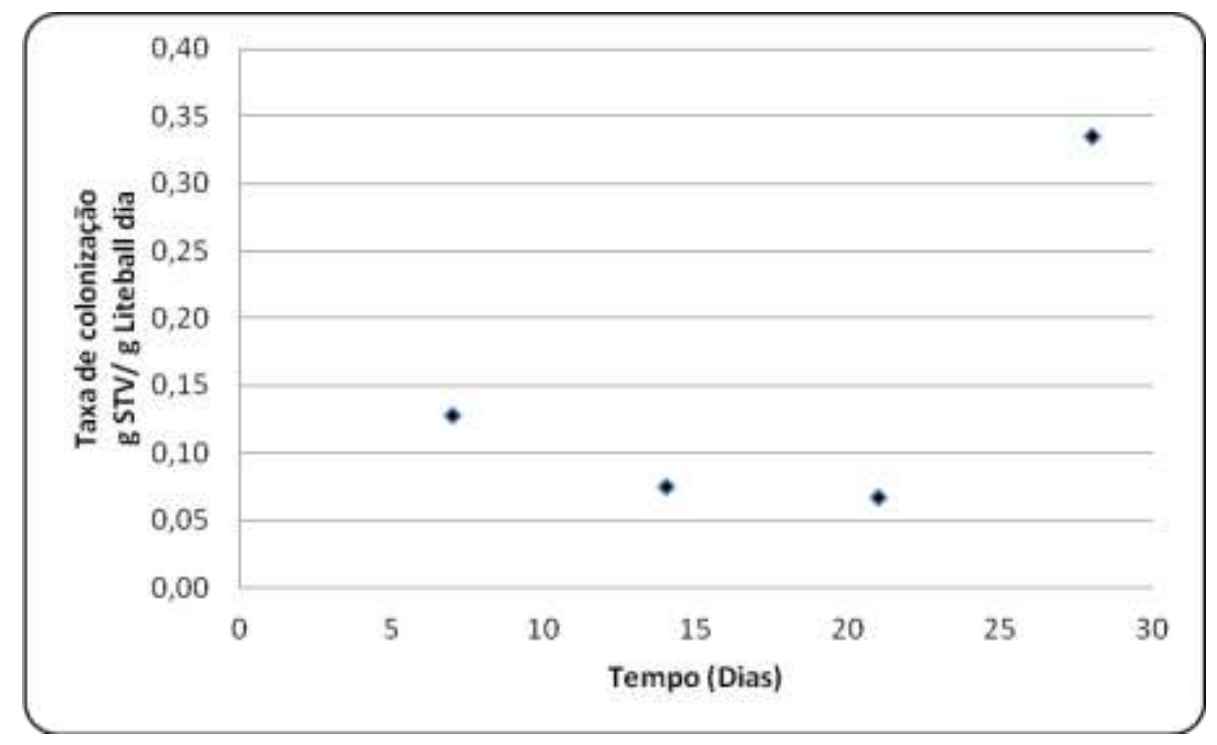

Figura 4 - Taxa de colonização dada em massa de sólidos voláteis totais por massa de material suporte por dia.

No período em que a taxa de colonização decaiu a retenção de sólidos apresentou comportamento inverso, porém de forma moderada.

Rodriguez e Zaiat (2011) obtiveram com uma relação $\mathrm{DQO} / \mathrm{SO}_{4}{ }^{-2}$ de 0,67 , uma retenção de biomassa máxima de aproximadamente $0,32 \mathrm{~g} \mathrm{STV} / \mathrm{g}$ espuma, e um decaimento da taxa de colonização ao longo do período experimentado, ou seja, 28 dias, (de 0,02433g STV/g espuma.dia para 0,00433g STV/g espuma.dia). Enquanto que no presente trabalho foi atingido retenção de sólidos de 9,38g STV/g Liteball e uma taxa de colonização de 0,33g STV/g Liteball.dia. Os resultados indicam que existe um potencial satisfatório para a adesão microbiana na partícula Liteball, que apresentou maior adesão em comparação com a espuma de poliuretano, além de maior taxa de adesão ao longo do tempo. Também houve decaimento da taxa de adesão nos 21 dias de ensaio com aumento no final do ensaio.

Os resultados deste trabalho mostraram que ainda são necessários testes complementares para que a avaliação da adesão microbiana na partícula de Liteball seja melhor analisada. A realização de ensaio em reatores diferenciais por período maior de tempo, ou seja, acima de 28 dias poderá confirmar o resultado obtido na última semana deste ensaio. Ainda poderão ser feitos testes com menor concentração de inóculo de modo a permitir adesão mais lenta da biomassa ao suporte no período inicial do ensaio.

De qualquer modo, pode-se notar que a partícula Liteball apresenta potencial para utilização como material suporte para imobilização de microrganismos. 


\section{CONCLUSÕES}

Os ensaios realizados permitiram concluir que a partícula Liteball apresenta potencial para utilização como material suporte para imobilização microbiana.

Para uma relação DQO/SO ${ }^{-2}{ }_{4}$ de 1,0 com DQO de $500 \mathrm{mg} / \mathrm{dm}^{3}$, a taxa de colonização observada foi de $0,3348 \mathrm{~g} \mathrm{SVT/g}$ suporte.dia para 28 dias de ensaio. Devido ao pequeno volume do reator foram observadas baixas conversões de sulfato e baixa remoção de carga orgânica.

Agradecimentos: os autores agradecem à empresa Mineração Curimbaba pelo apoio.

\section{REFERÊNCIAS}

AKCIL, A., KOLDAS, S. Acid mine drainage (AMD): causes, treatment and case studies. $J$. $C l$. Prod., v. 14, p. 1139-1145, 2006.

ALMEIDA, S.K. Detecção de bactérias redutoras de sulfato em efluente e sedimento de mina de urânio. Belo Horizonte/MG: Centro de Desenvolvimento da Tecnologia Nuclear. 2005.

APHA - AMERICAN PUBLIC HEALTH ASSOCIATION. Standard Methods for the examination for water and wastewater. New York: 2012.

CHERNICHARO, C.A. Reatores Anaeróbios. Belo Horizonte: DESA/Universidade Federal de Minas Gerais, 1997.

KNOBEL, A.N., LEWIS, A.E. A mathematical model of a high sulphate wastewater anaerobic treatment system. W. Res., v. 36, p. 257-265, 2002.

RIBEIRO, R., VARESCHE, M.B.A., FORESTI, E., ZAIAT, M. Influence of the carbon source on the anaerobic biomass adhesion on polyurethane foam matrices. J. Environ. Man. v. 74, p. 187-194, 2005.

MENEZES, C.T.B.; LEAL F ${ }^{\circ}$, L.S.; SANTO, E.L.; RUBIO J.; ROSA, J.J. DA; GALATTO, S.L.; IZIDORO, G. Tratamento de Drenagem Ácida de Mina: Experiência da Cabonífera Metropolitana. Florianópolis-SC: XX Encontro Nacional de Tratamento de Minérios e Metalurgia Extrativa, 2004.

RODRIGUEZ, R.P. Aplicação de reatores anaeróbios para remoção de sulfato de águas de drenagem ácida de minas. São Carlos: Escola de Engenharia de São Carlos, 2010.

RODRIGUEZ, R.P., ZAIAT, M. Bior. Tech., v. 102, p. 5060-5065, 2011.

RUBIO, J.; SILVA, R. Tratamento de Drenagem Ácida de Minas de Carvão: Tendências Tecnológicas. Rio Grande do Sul: Laboratório de Tecnologia Mineral e Ambiental da Universidade Federal do Rio Grande do Sul, 2012.

TANG, K,; BASKARAN, V.; NEMATI, M. Bacteria of the sulphur cycle: an overview of microbiology, biokinetics and their role in petroleum and mining industries. Bioch. Eng. J., v. 44, p. 73-94, 2009. 